\title{
Building Resilient Communities through Culturally Dynamic Partnerships
}

\author{
Narayan Gopalkrishnan \\ James Cook University, Cairns, Australia \\ *Corresponding Author: narayan.gopalkrishnan@jcu.edu.au
}

\begin{abstract}
Crisis in society can be caused by a number of social, political, environmental and economic factors including dramatic and immediate ones like the assassination of national leaders or the $9 / 11$ attacks in the United States, or they could be longer term ones like the Global Financial Crisis. They all have significant effects in terms of intense distress within individuals and communities. They also bring out the best and the worst in human responses. In particular, crises that can be directly or indirectly blamed on human agency are very prone to be turned into issues of racism and racist action across cultures and affect community resilience. Currently, cultural competence is a widely used method of developing the ability of people to manage inter-cultural relations, including issues of racism-related crisis. This paper will draw on the literature and research of cultural competency to argue that, while this method has some areas of strength, it also has some major failings such as the use of inappropriate terminology, lack of acknowledgement of the issues of power and racism, lack of cultural safety and the lack of acknowledgement of the dynamic nature of cultures. In this paper, the principles towards developing an alternative framework of Culturally Dynamic Partnerships (CDP) will be presented as a way towards enabling communities to deal with racism-related crises. This model would incorporate some of the most effective aspects of older models of cultural competence and cultural safety while going beyond some of the negative issues inherent in them.
\end{abstract}

Keywords Culturally Dynamic Partnerships, Cultural Competency, Cultural Safety, Crisis, Racism

\section{Introduction}

Notions of crisis are not new and the ideas reach back as far as Greek civilisation where the term was used in the sense of reaching the crucial point that would tip the scales and as Koselleck and Richter (2006, p. 361) argue, at that time the concept of crisis was applied to 'life-deciding alternatives meant to answer questions about what is just or unjust, what contributes to salvation or damnation, what furthers health or brings death. It could express long-term changes as well as occasional outbursts, apocalyptic expectations as well as sceptical fears'. Chun (2011) discusses crisis as a condensation of time that demands a decision and is intertwined often with political events and catastrophe which are linked with immediate subject-less events about death and the failure of technology.

There are a number of social, political, and environmental and economic factors that can lead to crisis in society. They may be direct and immediate as with the 9/11 attacks in New York and with the 2011 tsunami in Japan, or they may be more indirect and long-term as with the Global Financial Crisis or the effects of Climate Change. However they all share their effects, such as those of distress experienced by individuals and communities and implications on their abilities to cope with life (Bassilios, Reifels, \& Pirkis, 2012).

Crisis often has a disempowering and crippling effect on individuals, families and communities (Bassilios, Reifels, \& Pirkis, 2012). It can lead to the feeling of a need for a stable supportive power to enable survival. Crisis can also be a time when the extremes of human nature are at the forefront. Often environmental disasters are followed by exhilarating scenes of community solidarity and mutual support. The Brisbane Floods of 2011, while relatively less intense when compared to some of the natural disasters experienced across the world, are one example of this where the author was personally involved in as part of the community support. The images that emerged out of this disaster were a clear demonstration of community solidarity (Moore, 2011). However, there are many other crisis situations where people are intensely stressed and fearful and can turn on others as scapegoats to blame for the crisis situation. The darker side of human beings can often emerge at this time in the form of violent acts of racism, often impacting on those of minority cultures in society (Gopalkrishnan, 2013a). In the next section, some aspects of culture and its relationship with racism will be examined so as to provide the background to appropriate responses to crisis-related racism. 


\section{Culture and Racism}

Culture, as a term used in the public domain, is a very complex and contested one. In terms of this paper the term is used in its broadest sense as 'an abstract concept that refers to learned, shared patterns of perceiving and adapting the world which is reflected in the learned, shared beliefs, values, attitudes, and behaviours characteristic of a society or population' (Fitzgerald, Mullavey-O'Bryne, \& Clemson, 1997 , p. 3). It includes notions of race as a cultural construct, and also other aspects such as language, religion, nationality and socio-economic status as areas of difference (Bean, 2006).

Cultural identity is dynamic and as Kashima (2008, p. 108) states 'culture is continuously produced and reproduced by myriad individuals' everyday activities in interaction with each other. Without living and interacting persons there would be no living and evolving culture...' This dynamic nature of culture is also discussed by Spivak (2006) who argues that there is a tendency of powerful groups to view their own cultures as dynamic and other cultures as static. This dynamic nature of culture is often overlooked in many of the processes used to manage intercultural relations such as cultural competence and cultural safety, and this will be discussed a little later in the paper.

Human history is one of human interaction, and cultures have been interacting with each other over millennia. However, global interactions are growing at an exponential rate through the compression of the space-time continuum, a process enabled by advances in information and communication technology and travel infrastructure (Beck, 2000). Cultural interactions are also exponentially increasing as a result of globalization, many of which, such as those between migrants and receiving populations as well as between different migrant groups, can lead to conflict (Demeny, 2002). However, these conflicts are not only restricted to migrant situations as long established communities can be broken up on cross-cultural lines given the appropriate set of circumstances. Racism and discrimination, in particular, can play a key role in escalating the differences between individuals and groups in society (Babacan, 2005). Racism, in this context, incorporates all the elements earlier discussed about culture, in that it involves discrimination and domination that may be on the lines of language, religion, nationality, and ethnicity to name a few of the possible areas of difference (Babacan and Hollinsworth., 2009a). Racist movements across the world can often to be linked to the fear of the 'Other' which comes into play in the context of migration, and the development of parties like the 'One Nation' Party in Australia and the British National party are examples of migration politics (Quinn, 2003). The conflicts that centre on race can be extremely violent in some cases, as with the religion based conflicts in India that have resulted in thousands of deaths just in the last few decades, as for example the deaths in the Hindu-Muslim riots that followed the destruction, by Hindu Nationalists, of the Babri Masjid in India in 1992 (Gopalkrishnan, 2013b).

\section{Racism and Crisis}

Racism continues to be a vexed issue in modern society. At one level, the traditional form of racism, as a set of beliefs and behaviours based on the notion that biologically 'races' are inherently different, has been largely discredited (Babacan, 2008). This has however been replaced by ideas of 'cultural racism' and 'new racism' that continue to impact adversely on many groups in society (Babacan. and Hollinsworth, 2009a; Poynting \& Noble, 2004). Much of the discussion of racism in the public arena centres on overt racism, especially that involving violence or open discrimination. However, the last few decades have seen an overall reduction in the expressions of open racism, to be replaced by more hidden and covert racism. In their research with the constabulary in the UK, Holdaway and O'Neill (2007) point to exactly this phenomenon when they report that open forms of racism have been replaced by covert and hidden forms of individual and institutional racism. Coates (2008) also reflects on the significant effects of covert racism, which has significant adverse impacts on individuals and communities and yet remains very difficult to identify and to challenge. Because of these reasons, it becomes relatively safe for perpetrators to commit acts of covert racism without fear of condemnation or punitive actions, which is why covert racism remains the predominant form of racism experienced today (Holdaway \& O'Neill, 2007).

However, this situation changes dramatically during some forms of crises, especially those whose causes can be ascribed in some ways to human agency. Where a process of blame is possible, or made possible by leadership, overt racism can take place in an enabling moral climate (Gopalkrishnan, 2013a). The post 9/11 climate in the United States is a clear delineation of this phenomenon, with an immediate and dramatic increase in the number of anti-Islamic hate crimes documented by the Federal Bureau of Investigation as presented in the following chart. 


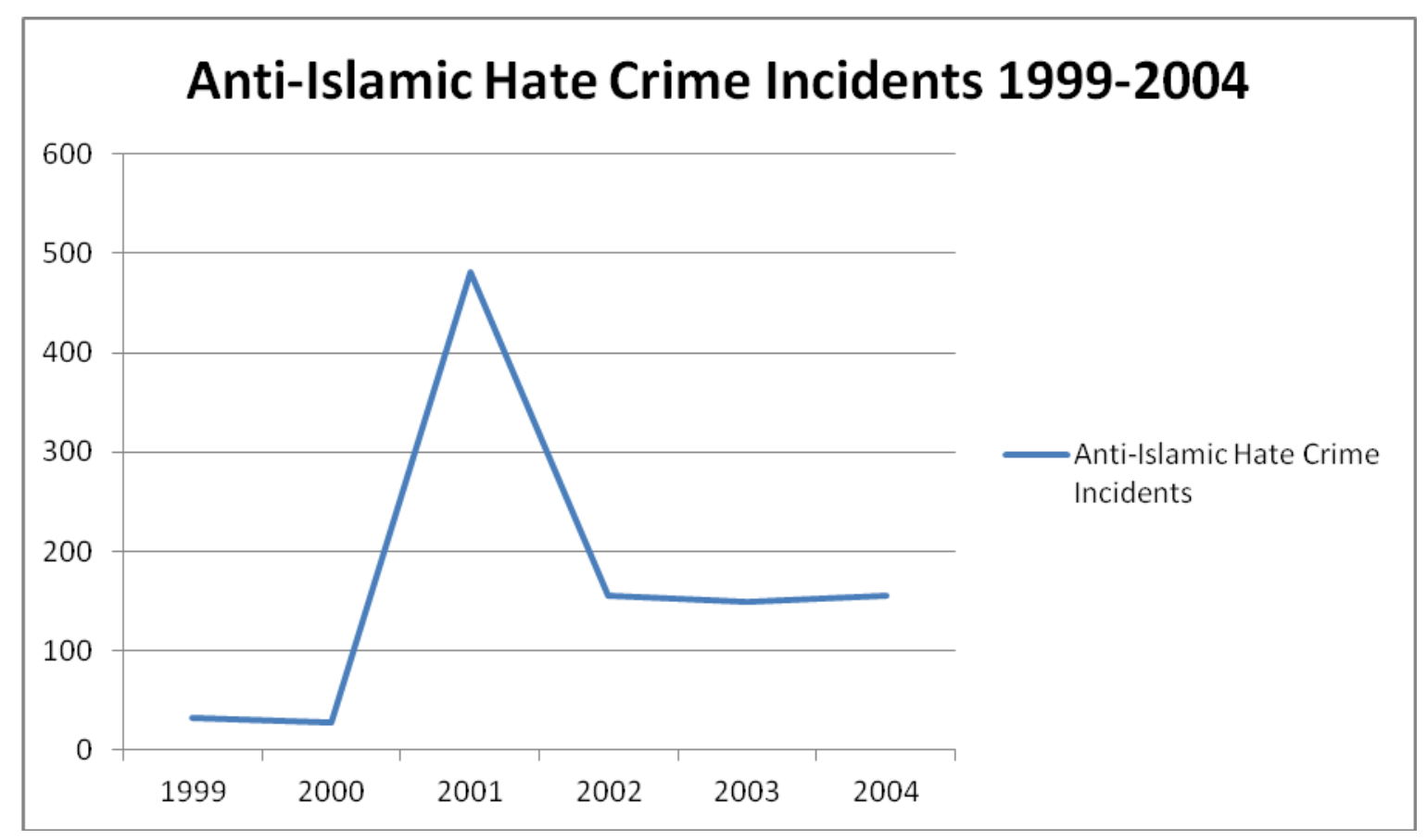

Source: US Federal Bureau of Investigation Hate Crime Statistics Annual Reports 1999-2004

(FBI, 1999)

The sharp increase of reported hate crimes following 9/11 is even more significant when considered with the fact that the overall figures of hate crimes are likely to be much higher given that there is manifest and huge underreporting of such occurrences to official authorities (Scott Poynting \& Mason, 2007). Even taking the figures at face value, there is clearly a sharp spike in hate crimes followed by a stabilisation at levels higher than before the spike. The figures continue to remain at high levels with a 130 incidents reported in 2012 (FBI, 2014). The fallout from 9/11 was also experienced in countries as far away as Australia where verbal abuse and physical violence towards Muslims increased substantially (HREOC, 2004; Poynting $\&$ Noble, 2004). The issues also can be exacerbated through a series of crises that can lead to an ongoing climate of fear and panic. The effects of such a series of crises were explored by the Anti-Discrimination Board of New South Wales in Australia, which found that that over the previous 18 months, debates in the media about September 11, the international 'war on terror', the prospect of US-led attacks on Iraq, the Tampa dispute, Australia's policies regarding asylum seekers, and the ongoing debates about law and order in Sydney, had the cumulative effect of generating a 'moral panic' in Australia (ADBNSW, 2003).

There are clear and compelling reasons for responses during crises of the categories, responses that can defuse the situation and ensure that overt racism and discrimination do not impact adversely on the people and communities. At a macro level, Coppola (2005) suggests that the notion of fear management be incorporated into policy and practice and that the media need to the assisted to act responsibly through a well-informed and educational public debate. At other levels, government representatives and trusted public professionals who interact with the public need to be informed and trained to effectively respond to public fears and concerns constructively (Newman, 2007). And finally individuals and communities need to develop the skills and attributes to enable them to respond constructively to crisis (Ife \& Tesoriero, 2006; Kenny, 2011a). What is common in all these responses is that people, at all levels, need to have the knowledge and skills that would enable them to work across cultures and mitigate some of some of the worst impacts of crisis (Landis, 2008). Cultural competency is often promoted as a model that helps develop the skills and knowledge requited to deal with these situation as also with wider issues of inter-cultural relations. In the next section, this model will be examined towards examining its appropriateness in dealing with racism-related crisis.

\section{Working across Cultures}

The last few decades have seen the widespread adoption of the notions of cultural competence, cultural safety, culturally inclusive practice, and cultural sensitivity as ways of enabling work across cultures, at least in countries like the United States, the United Kingdom and Australia. Of these, cultural competence is arguably the most commonly used approach (Bean, 2006). Cultural competence is described as 'a set of congruent behaviours, attitudes and policies that come together in a system, agency, or amongst professionals and enables that system, agency or those 
professionals to work effectively in cross-cultural situations... A culturally competent system... acknowledges and incorporates - at all levels - the importance of culture, the assessment of cross-cultural relations, vigilance towards the dynamics that result from cultural differences, the expansion of cultural knowledge, and the adaptation of services to meet culturally-unique needs' (Cross, Bazron, Dennis, \& Isaacs, 1989, p. iv). While this definition is quite dated it continues to be the most cited in the literature.

More recent definitions draw on the core ideas expressed by Cross and colleagues to apply them to specific contexts such as health or education (NCCC, 2014). Bean (2006, p. 23) has drawn on a number of these definitions to suggest that cultural competence 'refers to the awareness, knowledge and skills and the processes needed by individuals, profession, organisations and systems to function effectively and appropriately in culturally diverse situations in general and in particular encounters from different cultures'. Lum (1999, p. 175) expands on this to suggest that cultural competence 'is a process and arrival point'. This is also examined in the form of a continuum where individuals and organisations move back and forth, starting with cultural destructiveness, then cultural incapacity, cultural blindness, then a condition of cultural pre-competence, followed by cultural competence and finally cultural proficiency (NACCHO, 2011).

Most of the models of cultural competence focus on three areas of cultural competence:

- Self-awareness of the worker's own values, biases and power differences with clients. This includes recognition of the worker's own worldview, that it is also culturally constructed, and how that impacts on the interaction with the client, levels of ethnocentrism, an understanding of power and how it shapes thinking as well as an understanding of how this self-awareness will lead to more meaningful interactions.

- Knowledge of the practice environment, the helping methods and the client's culture. This would include knowledge about the culture that the client comes from as well as more generalized knowledge about how cultures vary and interact with each other. A common problem here is of cultural stereotyping which has the implicit assumption that all people from one culture share the same characteristics, an assumption that is often incorrect and leads to cross cultural conflict.

- Skills in verbal and non-verbal communication

(Bean, 2006; Gopalkrishnan, 2006; Lum, 1999).

Further, cultural competence is widely presented in the literature as involving four dimensions of practice. Firstly, at the individual level, it involves the development of knowledge, attitude and behaviours of the individual practitioner. Secondly, at the professional level, it involves education and professional development to guide the working lives of individuals. Thirdly, at the organisational level, it involves skill and resources as well as an organisational culture that values diversity and evaluates progress in the development of cultural competence. Finally, at the systemic level, it involves policies, procedures, monitoring mechanisms and resources that would support culturally competent practice at all levels (Eisenbruch, 2004; Bean, 2006).

Cultural competence is widely regarded as an effective model of working across cultures and forms the basis of much of the cross-cultural training that takes place in countries like Australia (Bean, 2006). However, over the last few years, many issues with the theory and practice of cultural competence have been raised, especially by Indigenous scholars, and some of the key aspects are discussed here.

Inappropriate Terminology: The very term 'cultural competence' is problematic in its suggestion that one can be competent at working across cultures (Dean, 2001). The Oxford Dictionary defines the term 'competence' as a mass noun that refers to the ability to do something successfully or efficiently (2014). The focus remains on what people do rather than on the knowledge that they have, which then extends into notions of outcomes rather than process, clearly defined standards of measurement of ability to perform tasks and timelines in which performance is measured (Smith, 2005). In the context of working across cultures, this focus on performance and the measurement of performance can lead to practice that is lacking in content, process and focus on genuine change. Further, the term carries with it the idea of a beginning and an end as discussed in the notion of a continuum from cultural destructiveness to cultural proficiency (NACCHO, 2011). This is also problematic as the dynamic and changing transformation of cultures and the complex nature of interactions would imply that nobody could ever be competent and proficient at working across cultures. In fact, Dean (2001, p. 628) suggests that it may be better to approach cross-cultural work with an appreciation of one's own lack of competence so as to 'participate in the ongoing processes of seeking understanding and building relationships'.

Lack of acknowledgement of issues of power and racism: Very little of the literature of cultural competency examines the issues that power or the lack of power raise within cross-cultural interactions. Sakamoto (2007, p. 108) states that ' $(w)$ here analyses of power are lacking or inadequate, culture is seen as neutral, thereby allowing the systems of oppression (such as racism, ageism, homophobia, Islamophobia, ableism) that initially motivated the call for cultural competence to disappear into the background'. Pon (2009, p. 60) carries this argument further, suggesting that the processes of cultural competence resemble 'new racism by otherizing non-whites by deploying modernist and absolutist views of culture, while not using racialist language'. Issues of racism and the historical context of 
colonization that continues to play a key role in many countries do not form a core element of cultural competence theory, raising the question of the relevance of practice that is not established within the reality of the situation (Sakamoto, 2007). In the area of racism-related crisis, this becomes a fatal flaw to the use of cultural competence to work across the different cultures involved in the situation. If issues of race and racism are not acknowledged, the likelihood of working through the crisis diminishes considerably.

Another element that is implicated within the power dimension is the lack of cultural safety that the participants involved in cultural competence can experience. There is a considerable body of literature around the term 'cultural safety' which suggests that the space for cross-cultural interaction can be overladen with issues of power differentials and racism and there needs to be a deliberate effort towards establishing culturally safe spaces if cross-cultural interactions have to be constructively engaged in (NACCHO, 2011; Skellet, 2012; Williams, 1999). As described by Williams (1999, p. 213) cultural safety is 'an environment, which is safe for people; where there is no assault, challenge or denial of their identity, of who they are and what they need. It is about shared respect, shared meaning, shared knowledge and experience, of learning together with dignity, and truly listening'. This idea of a safe environment is critical when dealing with issues of race-related crisis as it is a time when marginalised groups can feel threatened and that their identities are being attacked. There are many examples of people having to hide their religious identities after crisis situations, such as Sikhs cutting their long hair and Muslims shaving their beards.

Much of the literature and practice of cultural safety has emerged out of Indigenous scholarship and practice in New Zealand, Australia and Canada, where histories of colonisation have impacted severely on Indigenous communities over generations (Bin-Sallik, 2003; Skellet, 2012). While cultural safety incorporates a number of useful principles such as respect for culture and knowledge, clearly defined pathways to empowerment and self-determination, and recognition of more than one way of doing things (NACCHO, 2011; Williams, 1999), it continues to suffer from a lack of clarity and consistency in practice, and the focus on Indigenous populations does not allow for applicability to work with culturally and linguistically diverse populations in society (Manchester, 2013).

Lack of acknowledgement of the dynamic nature of cultures: As discussed earlier in this paper, culture is dynamic and interactions between different cultures add to the nature and extent of change in cultures. A major issue with the cultural competence model is that it continues to view cultures as static and immutable and it can be learnt about and this learning can be assessed. As stated by Pon (2009, p. 63) 'cultural competency assumes, not unlike Thatcher and Huntington, that culture is a collection of absolute, stable, fixed objective traits and values'. Another aspect of this issue is raised by Spivak (2006) in the context of two areas of study, that of Anthropology and Cultural Studies, where the former explores other's cultures as static and the latter examines one's own culture as dynamic and evolving, clearly a problematic and political issue. The same arguments could easily be made in relation to cultural competence practitioners, that they fall into two groups in terms of how they view culture. One group perceives all cultures as static, including their own, while the second group, of more self-reflexive practitioners, would see their own culture evolving with each interaction but continue to view the other's culture as static. Both of these positions do not acknowledge the true nature of cultural interaction; that both cultures are dynamic and evolve with each interaction.

These issues of inappropriate terminology, lack of acknowledgement of issues of power and racism, and the lack of acknowledgement of the dynamic nature of cultures are definite problems with how cultural competence is theorized and implemented as a way of working across cultures. It is of particularly issue in terms of working with crisis situations where racism is likely to play a part, as it does not acknowledge issues of racism as core to inter-cultural relations. There is clearly a need for a better, more inclusive model of cross-cultural work in general and in racism-related cross-cultural work specifically.

\section{Culturally Dynamic Partnerships (CDP)}

The concept of Culturally Dynamic Partnerships draws on some of the important elements of both cultural competence and cultural safety while modifying them through the application of a set of principles that have relevance towards both. There are a number of elements of the model of cultural competence that are useful towards developing a more effective way of working across cultures. The levels of practice at the individual, professional, organisational and the systemic can be easily incorporated into any new conceptualisation. The notions of looking at the worker's own self-awareness, knowledge and skills are also useful in terms of a new model. The idea of a culturally safe environment for cross-cultural interaction should also be integral to the conceptualisation. However, to ensure that some of the problems raised in the previous section are addressed, a set of guiding principles are presented as a basis for developing further theory and practice.

\section{1- Use appropriate terminology}

It would be useful to start with a term that moves away from traditional disempowering and top-down approaches. The term Culturally Dynamic Partnerships (CDP) is presented as one that incorporates an acknowledgement of the dynamic nature of cultures while rejecting ideas of 'doing something to the other' which is implicit within words like 'competence' and 'practice' (the author considered the latter before rejecting it for precisely the reasons stated). The idea that inter-cultural practice does not 
happen only on the part of the 'professional practitioner' needs to be acknowledged and the collaborative element of partnership would be an appropriate beginning. The use of appropriate terms would be of particular note in race-related crisis situations where the efforts have to be directed towards negating the polarizing effects of racism and bringing people closer together in collaborative partnerships.

\section{2- Consider every culture a dynamic culture and every interaction a dynamic interaction}

One has to acknowledge that one's own culture is constantly changing and so is the culture of the person one is interacting with. The implication of this is that any prior knowledge that one has about the culture of the other has to be treated as inadequate and verified through collaborative learning during interaction. Every interaction is a learning interaction for all participants and leads to cultural changes that modify future interactions. Issues of cultural stereotyping and absolutist views of cultures, which are often at the heart of race-related crisis, can be managed much more effectively if many more people involved had a clear understanding of the dynamic and evolving nature of cultures. CDP would involve people from different cultures coming together in collaborative learning interactions that would help in terms of developing mutual understanding and help to discredit the stereotypes that are from the heart of race related crisis.

\section{3- Consider every interaction as a collaborative partnership and based on power-sharing}

As discussed earlier, issues of power or lack of power can play a key role in cross-cultural interactions, and especially problematic in the context of racism related crisis. Marginalised cultural groups can be excluded quite easily if issues of power are not addressed effectively (Sakamoto, 2007). CDP works on the principles of collaboration and partnership as central to practice. While, these principles guide the interaction between organisations and communities, they also extend to guide interactions between different groups in society and individuals within and across groups. CDP practitioners would work actively towards ensuring that power is shared as evenly as possible among the different stakeholders. This would also involve a continuing process of training, development and self-empowerment of all stakeholders.

4- Acknowledge the nature and impact of racism on communities and individuals and the historical context in which racism is enacted.

Working within CDP would involve developing an understanding of the nature and impact of racism on communities and individuals in the communities. The nature of both overt and covert expressions of racism in society need to be examined and CDP would include a broad-based understanding of the historical context of racism especially in postcolonial settings. This would also mean that every stakeholder in CDP would repeatedly examine their positioning in terms of power relationships both in historical and contemporary contexts and seek to transform relationships towards more collaborative and power-sharing ones. The nature of crisis, especially those that lead to racism, will also be examined so as to develop effective and sustainable ways of moving forward collaboratively.

\section{5- Work towards developing a culturally safe environment for cross-cultural interaction}

The notion of cultural safety is of vital importance to ensure positive outcomes from cross-cultural interaction. If participants feel that they are unsafe, or that their cultural identity is denied or challenged, there is every likelihood of further rifts in society and exacerbation of the negative impacts of racism. Some of the principles delineated by Williams (1999) would be central to incorporating cultural safety into CDP practice. They would include recognition of more than one way of doing things, working with where people are at and not where professionals want them to be, the right to make mistakes and learn from mistakes, mutual respect of culture, knowledge, experience and obligations, ensuring no assault on a person's identity or dignity, and the recognition of the right to promote, develop, and maintain own institutional structures, distinctive customs, traditions, procedures and practices (Williams, 1999, p. 214). They would also include environmental changes that are inclusive of different cultures and traditions and build on the strengths of diversity (Skellet, 2012).

\section{6- Collaboratively develop skills across the range of micro-mezzo-macro skill sets}

The discussion on skills in cultural competency literature stays largely in the realm of verbal and non-verbal communication skills that need to be adapted to work across cultures (Bean, 2006). However, the breadth of work required in crisis situations would require a range of skills. The first of these are of course the micro-skills of communication. At the mezzo level there are a broad range of skills to work with communities to build increased participation and community capacity and ensure social inclusion (Kenny, 2011b). In an earlier publication, the author has argued for the development of a range of skills for challenging racism and discrimination at three levels of practice, at the micro, mezzo and macro levels (Gopalkrishnan, 2008). And at the macro level, skills would be needed for policy development as well as for turning policy into practice to ensure the best outcomes in crisis situations.

\section{7- Draw on the key elements of cultural competence, while modifying them using the principles of CDP}

As the cultural competence, the areas of attitude, knowledge and skills need to be developed in culturally 
dynamic practice across many levels including the individual, the professional, the organisational and the systemic. However, a key element of CDP is that the development occurs in partnership with the community, which implies that many stakeholders would be involved in the process including leaders of the community as well as many others who would, in turn, disseminate their training in the community. At the individual level, CDP can be nurtured among people in the community, human service professionals, support staff as well as senior staff in support organisations. At the professional level, all professionals working with the community such as doctors, social workers, mental health professionals and others need to have culturally dynamic practice standards as part of their professional standards and also have it built into their professional degrees. In terms of organisations working with communities, and in particular communities that are affected by race-related crisis, the organisational culture should value culturally dynamic practice and encourage cultural diversity within the organisation. Notions of consumer participation and community participation in organisations would also form a key part of CDP to ensure that organisations respond effectively to the needs of the community. Finally, at the systemic level, appropriate policies and procedures need to be developed to support CDP and sufficient resources provided to ensure sustainable outcomes.

\section{Closing Discussion}

The principles of CDP as delineated in the previous section are effective principles to guide interactions across cultures in all situations. They are useful towards ensuring that all stakeholders in the interactions are well equipped to work towards effective collaborations and positive process and outcomes. However, these principles assume much greater significance in the context of crisis in society that has racism implications. As discussed earlier in the paper, some forms of crisis can lead to dramatic increases in overt forms of racism that can impact in adverse ways on minority groups in society (HREOC, 2004; Poynting \& Noble, 2004). The responses to these forms of crisis need to be immediate, well-informed and at all levels including the micro-mezzo-macro levels. Ensuring that the key stakeholders are trained and resourced to work with CDP principles and practice will ensure that the responses that are undertaken are appropriate and effective and not just knee-jerk responses based on insufficient information. This is especially important in today's world of shared global risk where the number and impact of crises across nations seems to be rising at an exponential rate and, as Kosseleck and Richter (2006) argue, the modern period could be considered the age of crises. Working effectively across cultures is increasingly not an add-on to individuals and organisations, it is a central part of practice, and the adoption of CDP principles would be a major step in that direction.

\section{REFERENCES}

ADBNSW. (2003). Race for the Headlines: Racism and media discourse, from http://pandora.nla.gov.au/tep/39681

Babacan, H. (2005). Challenges of Inclusion: Cultural Diversity, Citizenship and Engagement. refereed proceedings of International Conference on Engaging Communities. Retrieved from http://www.engagingcommunities2005.org/ab-theme-10.html

Babacan, H. (2008). Addressing Denial: The First Step in Responding to Racism. In H. Babacan \& N. Gopalkrishnan (Eds.), The Complexities of Racism: Proceedings of the Second International Conference on "Racisms in the New World Order. Queensland: University of the Sunshine Coast.

Babacan H. and Hollinsworth D. (2009a). A final report on the nature and extent of racism in Queensland. Australia: Centre for Multicultural Pastoral Care.

Bassilios, B., Reifels, L., \& Pirkis, J. (2012). Enhanced Primary Mental Health Services in Response to Disaster. Psychiatric Services, 63(9), 868-874.

Bean, R. (2006). The Effectiveness of Cross-Cultural Training in the Australian Context. Canberra: Department of Immigration and Multicultural Affairs.

Beck, U. (2000). What is Globalization? Cambridge: Polity Press.

Bin-Sallik, M. (2003). Cultural Safety: Lets Name It! Australian Journal of Indigenous Education, 32, 21-28.

Chun, W. H. K. (2011). Crisis, Crisis, Crisis, or Sovereignty and Networks. Theory, Culture \& Society, 28(6), 91-112. doi: $10.1177 / 0263276411418490$

Coates, R. D. (2008). Covert Racism in the USA and Globally. Sociology Compass 2(1), 208-231.

Competence. (2014). In Oxford Dictionaries Retrieved 10/09/2014, from

http://www.oxforddictionaries.com/definition/english/competence

Coppola, D. P. (2005). "Gripped by fear": Public risk (mis)perception and the Washington, DC sniper. Disaster Prevention and Management, 14(1), 32-54.

Dean, R. G. (2001). The myth of cross-cultural competence. Families in Society, 82(6), 623-630.

Demeny, P. (2002). Prospects for International Migration: Globalization and its Discontents. Journal of Population Research, 19(1), 65-74. doi: $10.2307 / 41110739$

Eisenbruch, M. (2004). The Lens of Culture, the Lens of Health: Toward a Framework and Toolkit for Cultural Competence. Sydney: Centre for Culture and Health, The University of New South Wales.

FBI. (1999). Hate Crime Statistics Annual Report. Washington: Federal Bureau of Investigation.

FBI. (2000). Hate Crime Statistics Annual Report. Washington: Federal Bureau of Investigation.

FBI. (2001). Hate Crime Statistics Annual Report. Washington: Federal Bureau of Investigation. 
FBI. (2002). Hate Crime Statistics Annual Report. Washington: Federal Bureau of Investigation.

FBI. (2003). Hate Crime Statistics Annual Report. Washington: Federal Bureau of Investigation.

FBI. (2004). Hate Crime Statistics Annual Report. Washington: Federal Bureau of Investigation.

FBI. (2012). Hate Crime Statistics Annual Report. Washington: Federal Bureau of Investigation.

Fitzgerald, M. H., Mullavey-O'bryne, C., \& Clemson, L. (1997). Cultural issues from practice. Australian Occupational Therapy Journal, 44, 1-22.

Gopalkrishnan, N. (2008). Anti-Racist Cultural Competence: Challenges for Human Service Organizations. In H. Babacan \& N. Gopalkrishnan (Eds.), The Complexities of Racism: Proceedings of the Second International Conference on "Racisms in the New World Order". Qld.: University of the Sunshine Coast.

Gopalkrishnan, N. (2013a). From Covert to Overt: The Role of Crisis in Transforming Racism. In N. Gopalkrishnan \& H. Babacan (Eds.), Proceedings of the Third International Conference on Racisms in the New World Order: Realities of Culture, Colour and Identity. (pp. 95-105). Cairns, Qld: James Cook University.

Gopalkrishnan, N. (2013b). India: A Country Report. In H. Babacan \& P. Hermann (Eds.), Nation state and Ethnic Diversity. New York: Nova Science Publishing.

Holdaway, S., \& O'Neill, M. (2007). Where has all the racism gone? Views of racism within constabularies after Macpherson. Ethnic and Racial Studies, 30(3), 397-415. doi: $10.1080 / 01419870701217480$

HREOC. (2004). Isma /Listen: National Consultations on Eliminating Prejudice Against Arab and Muslim Australians. Sydney: Human Rights and Equal Opportunities Commission.

Ife, J., \& Tesoriero, F. (2006). Community Development: Community Based Alternatives in an Age of Globalisation (3 ed.). Frenchs Forest: Pearson Education Australia.

Kashima, Y. (2008). A Social Psychology of Cultural Dynamics: Examining How Cultures Are Formed, Maintained, and Transformed. Social and Personality Psychology Compass, 2(1), 107-120.

Kenny, S. (2011a). Developing Communities for the Future. South Melbourne: Cengage Learning.

Kenny, S. (2011b). Towards unsettling community development. Community Development Journal, 46(suppl 1), i7-i19.

Koselleck, R., \& Richter, M. (2006). Crisis. Journal of the History of Ideas, 67(2), 357-400.

Landis, D. (2008). Globalization, migration into urban centers, and cross-cultural training. Journal of Intercultural Studies, 32, 337-348.

Lum, D. (1999). Culturally competent practice: A framework for growth and action. Pacific Grove CA: Brooks/Cole.

Manchester, A. (2013). Cultural Safety Should Be Reviewed. Kai Tiaki Nursing, 19(9), 14.

Moore, T. (2011). Council salutes mud army, Brisbane Times. Retrieved from http://www.brisbanetimes.com.au/queensland/council-salutes-mud -army-20110208-1altl.html

NACCHO. (2011). NACCHO Cultural Safety Training Standards: A background paper. Canberra: National Aboriginal Community Controlled Health Organisation.

NCCC. (2014). Definitions of Cultural Competence Retrieved $7 / 10 / 2014$, from

http://www.ncccurricula.info/culturalcompetence.html

Newman, N. (2007). The new frontier of racism. Public Policy Research, 14(2), 80-89. doi: 10.1111/j.1744-540X.2007.00470.x

Pon, G. (2009). Cultural Competency as New Racism: An Ontology of Forgetting. Journal of Progressive Human Services, 20(1), 59-71. doi: 10.1080/10428230902871173

Poynting, S., \& Mason, V. (2007). The resistible rise of Islamophobia : Anti-Muslim racism in the UK and Australia before 11 September 2001. Journal of Sociology, 43(1), 61-86. doi: $10.1177 / 1440783307073935$

Poynting, S., \& Noble, G. (2004). Living with Racism: The experience and reporting by Arab and Muslim Australians of discrimination, abuse and violence since 11 September 2001 Report to the Human Rights and Equal Opportunity Commission (pp. 1-20). Sydney: Centre for Cultural Research, University of Western Sydney.

Sakamoto, I. (2007). An Anti-Opressive Approach To Cultural Competence. Canadian Social Work Review / Revue canadienne de service social, 24(1), 105-114. doi: 10.2307/41669865

Skellet, L. (2012). Cultural awareness and cultural safety. Australian Pharmacist, 31(5), 382-384.

Smith, M. K. (2005). Competence and competencies. The encyclopaedia of informal education. Retrieved from www.infed.org/biblio/b-comp.htm

Spivak, G. C. (2006). Culture Alive. Theory, Culture \& Society, 23(2-3), 359-360. doi: 10.1177/026327640602300264

Williams, R. (1999). Cultural Safety-What Does It Mean for Our Work Practice? Australian and New Zealand Journal of Public Health, 23, 213-214. 